\title{
Simulated versus traditional occupational therapy placements: A randomised controlled trial.
}

\section{Authors}

Professor Christine Imms, BAppSc(OT), MSc, PhD. Professor of Occupational Therapy, National Head of School of Allied Health, Locked Bag 4115, Fitzroy, VIC 3065, Australia; Australian Catholic University; Christine.imms@acu.edu.au Associate Professor Elspeth Froude, BAppSc(OT), GradDip(NeuroSc), PhD. Associate Professor (Discipline Lead) in Occupational Therapy, Deputy Head of School (Sydney) School of Allied Health, Australian Catholic University; PO Box 968, North Sydney, NSW, 2059, Australia; Elspeth.froude@acu.edu.au

Dr Eli Mang Ye, Chu, BSc(OT), PhD, GCHE, at the time of the study was employed in the role of Lecturer, School of Allied Health, Australian Catholic University, Locked Bag 4115, Fitzroy, VIC 3065, Australia; From June, 2017, Senior Lecturer in Occupational Therapy, School of Primary and Allied Health Care, Monash University, PO Box 527, Frankston, VIC 3199, Australia; Eli.Chu@monash.edu

Associate Professor Loretta Sheppard, BAppSc(OT), MOT, DClinSci. Associate Professor, National Professional Practice Coordinator, School of Allied Health, Locked Bag 4115, Fitzroy, VIC 3065, Australia; Loretta.sheppard@acu.edu.au

Dr Susan Darzins, BAppScOT, MMedSc (Clin Epi), PhD; Senior Lecturer in Occupational Therapy, Course Coordinator (Melbourne), School of Allied Health, Locked Bag 4115, Fitzroy, VIC 3065, Australia; Susan.Darzins@ acu.edu.au

Dr Stephen Guinea, GradDipVocTrainDevelop, BN, PhD., Senior lecturer, Faculty Coordinator of Health Simulation, Faculty of Health Sciences, Australian Catholic University, Locked Bag 4115, Fitzroy, VIC 3065, Australia; Stephen.Guinea@acu.edu.au Ms Elena Gospodarevskaya, MEcon, PostGradDip.Bus (FM\&Ec), PostGradDip.HEcEv. Deakin Health Economics, Centre for Population Health Research, Deakin University, Geelong, Victoria, Australia; elena.gospodarevskaya@deakin.edu.au Professor Rob Carter, BA (Econs); M Admin Studies; Grad Dip Epi; PhD. Alfred Deakin Professor (Health Economics), Deakin Health Economics, Centre for Population Health Research, Deakin University, Geelong, Victoria, Australia; rob.carter@ deakin.edu.au

This is the author manuscript accepted for publication and has undergone full peer review but has not been through the copyediting, typesetting, pagination and proofreading process, which may lead to differences between this version and the Version of Record. Please cite this article as doi: $10.1111 / 1440-1630.12513$

This article is protected by copyright. All rights reserved 
Dr Mark A. Symmons, PhD, at the time of the study was employed in the role of Project Manager, School of Allied Health, Australian Catholic University, Locked Bag 4115, Fitzroy, VIC 3065; mark.symmons1@gmail.com

Dr Merrolee Penman, DipOT, GradDipHlthSci(OT), DipTeach(Tert), MA(Educ), EdD., Senior Lecturer, Work Integrated Learning, Faculty of Health Sciences, The University of Sydney, NSW, 2006, Australia; merrolee.penman@sydney.edu.au

Ms. Kelli Nicola-Richmond, B. Physiotherapy(Hons), GCHE, Senior Lecturer in Occupational Therapy, School of Health and Social Development, Deakin University, Locked Bag 20000, Geelong Vic Australia, 3220, Australia;

k.nicolarichmond@deakin.edu.au

Ms. Susan Gilbert Hunt, M.Hlth.Sc(OT), Cert.Edu, DipCOT, Senior Lecturer in Occupational Therapy, School of Health Sciences, University of South Australia, GPO Box 2471, Adelaide, SA 5000, Australia; susan.gilbert-hunt@unisa.edu.au

Mr. Nigel Gribble, MBA BSc(OT)(Hons), Lecturer, School of Occupational Therapy, Social Work, and Speech Pathology, Faculty of Health Sciences, Curtin University, GPO Box U1987, Perth, WA, 6845, Australia; n.gribble@ curtin.edu.au

Dr Samantha Ashby, DipCOT, BSc(Hons), M.App.Sci (Research OT), PhD, Senior Lecturer, School of Health Sciences (Occupational Therapy), University of Newcastle, University Drive, Callaghan, NSW, 2308, Australia; $\underline{\text { Samantha.ashby@ newcastle.edu.au }}$ Dr Erin Mathieu, BEd, MPH(Hons) PhD. Lecturer, Sydney School of Public Health, Edward Ford Building, The University of Sydney, NSW 2006, Australia;

erin.mathieu@sydney.edu.au

\section{Authors' declaration of contributions}

CI led the conception and design and RCT implementation, analysis and interpretation of the findings, and drafted and revised the manuscript. EF contributed to the original design, led site-based implementation, and contributed to data acquisition. EMYC, LS, SG contributed to the design of the simulation and trial implementation. SD contributed to the original design and trial implementation. EG, RC led the design and acquisition of economic data alongside the RCT. MAS contributed to the project implementation and acquisition of data as project manager. MP, KNR, SGH, NG, SA contributed to the original design as partner investigators and led site-based implementations. EM led the statistical analysis. All authors contributed to interpretation of findings, critically reviewed the manuscript, gave approval for publication and agreed to be accountable for all aspects of the work. 


\section{Funding statement}

This project was funded by the Commonwealth Department of Health within the Workforce

Development and Innovation program.

\section{Conflict of interest statement}

The authors declare no conflicts of interest.

\section{Trial registration}

ACTRN12616001339448, http://www.ANZCTR.org.au/ACTRN12616001339448.aspx,

As the trial did not assess a health outcome, it was retrospectively registered on 26 September 2016 .

\section{Trial protocol publication}

Imms, C., Chu, E. M. Y., Guinea, S., Sheppard, L., Froude, E., Carter, R., . . Symmons, M. (2017). Effectiveness and cost-effectiveness of embedded simulation in occupational therapy clinical practice education: study protocol for a randomised controlled trial. Trials, 18(1), 345. doi: 10.1186/s13063-017-2087-0

\section{Acknowledgements}

We thank the student participants for their willingness to take part in this study. Contributions to the development of materials, the implementation of the RCT and the SCP on each site, and the examination markers are acknowledged. We also acknowledge Mario D’Souza (University of Sydney) and Alice Ames (Australian Catholic University) who contributed to the data analysis, and the central project management team, including Mirna Boujaoude (National Research Assistant), and Tanya Edlington (National Training Officer). We also thank our project oversight board which comprised representatives from the Commonwealth Department of Health, Occupational Therapy Board of Australia, Occupational Therapy Council (Australia and New Zealand), and Australia and New Zealand Council of Occupational Therapy Education, and state that these entities received reports but had no role in the implementation of the trial or analysis and interpretation of trial outcomes.

\section{Word counts}

Abstract: 296

Main text: 3516 
Number of references: 34

Number of Tables: 4

Number of Supplementary Figures and Tables: 2 Figures and 2 Tables

\section{Corresponding author}

Christine Imms: Professor of Occupational Therapy, National Head of School of Allied Health, Locked bag 4115, Fitzroy, VICTORIA, Australia, 3065; +61399533404;

Christine.imms@acu.edu.au

\section{MeSH terms}

Simulation training, education-professional, occupational therapy, randomised controlled trial, professional competence

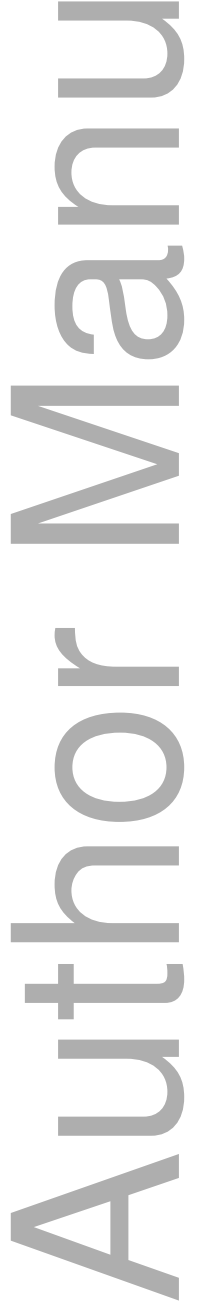


PROF. CHRISTINE IMMS (Orcid ID : 0000-0001-9055-3554)

DR. ELSPETH HEATHER FROUDE (Orcid ID : 0000-0002-6863-2317)

MRS. SUSAN DARZINS (Orcid ID : 0000-0003-1852-3566)

DR. MERROLEE PENMAN (Orcid ID : 0000-0002-4802-2052)

Article type : Feature Article

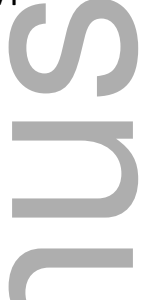

Abstract

Introduction: Professional practice placements in occupational therapy education are critical to ensuring graduate competence. Australian occupational therapy accreditation standards allow up to 200 of a mandated 1000 placement hours to include simulation-based learning. There is, however, minimal evidence about the effectiveness of simulation-based placements compared with traditional placements in occupational therapy. We evaluated whether occupational therapy students completing a 40 hour (one-week block) Simulated Clinical Placement (SCP) attained non-inferior learning outcomes to students attending a 40-hour Traditional Clinical Placement (TCP).

Methods: A pragmatic, non-inferiority, assessor-blinded, multicentre, randomised controlled trial involving students from six Australian universities was conducted. Statistical power analysis estimated a required sample of 425 . Concealed random allocation was undertaken with a 1:1 ratio within each university. Students were assigned to SCP or TCP in one of three settings: vocational rehabilitation, mental health or physical rehabilitation. SCP materials were developed, manualised and staff training provided. TCPs were in equivalent practice areas. Outcomes were assessed using a standardised examination, unit grades, the Student Practice Evaluation Form-Revised, and student confidence survey. A generalised estimating equation approach was used to assess non-inferiority of the SCP to the TCP.

This article is protected by copyright. All rights reserved 
Results: Of 570 randomised students ( $84 \%$ female), 275 attended the SCP and 265 the TCP ( $n=540,94.7 \%$ retention). There were no significant differences between the TCP and SCP on i) examination results (marginal mean difference $1.85,95 \% \mathrm{CI}$ : 0.46 to 3.24 ; $\mathrm{p}=0.087$ ); ii) unit score (mean (SD) SCP: 71.9(8.8), TCP: 70.34(9.1); $\mathrm{p}=0.066$ ); or iii) placement fail rate, assessed using the Student Practice Evaluation Form-Revised (100\% passed both groups).

Conclusion: Students can achieve equivalent learning outcomes in a 40-hour simulated placement to those achieved in a 40-hour traditional placement. These findings provide assurance to students, educators and professional accreditation bodies that simulation can be embedded in occupational therapy education with good effect.

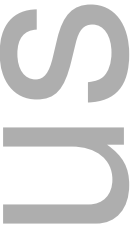

\section{Introduction}

Practice placements are integral to health professional education, including occupational therapy. Theoretical knowledge derived from formal education must be supported by experience in the practice environment to maximise learning and establish professional competence (Hager, 2011; Oppermann \& Specht, 2006; Svensson, Ellström, \& Åberg, 2004). As part of international (World Federation of Occupational Therapists, 2002) and national (Occupational Therapy Council, 2013) accreditation requirements, occupational therapy students must complete 1000 hours of placement. However, universities can have difficulty sourcing sufficient placements that provide quality learning experiences to ensure students achieve professional competencies across a range of practice areas (Gustafsson, Brown, McKinstry, \& Caine, 2016; Rodger et al., 2008).

Simulation has been shown to contribute positively to the education of students in a range of professions including medicine (Brydges, Hatala, Zendejas, Erwin, \& Cook, 2015; Eagles, Calder, Wilson, Murdoch, \& Sclare, 2007), nursing (Bradley, 2006; Harder, 2009; Ricketts, 2011), and allied health (Mori, Carnahan, \& Herold, 2015; Yeung, Dubrowski, \& Carnahan, 2013). Occupational therapy literature also describes the benefits of simulation for training and education (Reed, 2014), although there is a paucity of rigorous evaluations (Bennett, Rodger, Fitzgerald, \& Gibson, 2017). Whether it can replace a traditional placement requires empirical evaluation. We conducted a randomised controlled trial (RCT) to investigate the effectiveness of a 40This article is protected by copyright. All rights reserved 
hour simulated clinical placement (SCP) compared to a traditional clinical placement (TCP). The SCP design was informed by:

1. key elements of practice education, including learner level and learning outcomes, practice context and processes (Townsend \& Polatajko, 2013);

2. quality criteria for simulation based placements (Rodger, Bennett, Fitzgerald, \& Neads, 2010);

3. theoretical perspectives deemed essential for authentic learning (Eraut, 2007; Herrington \& Oliver, 2000); and

4. activities and processes that can be included in a simulation experience (Eraut, 2007, 2010).

Prior to this study, a one-week (40 hours) SCP for second-year occupational therapy students in one university was successfully trialled as a replacement for a oneweek TCP in a vocational rehabilitation setting (Imms et al., 2014). Principles underpinning the trial SCP design were organised to form the Conceptual Framework for Simulated Clinical Placements (CF-SCP) (Chu, Sheppard, Guinea, \& Imms, under review). The CF-SCP supports educational choices when designing a quality simulation learning experience and was used to inform the development of two additional occupational therapy SCPs for this study in mental health and physical rehabilitation settings.

The overall aims of the RCT were to test the educational outcomes, cost and costeffectiveness of a one-week SCP designed according to the CF-SCP. Comparative costs (Gospodarevskaya et al., Submitted) and outcomes related to student and supervisors perceptions of the value of simulated placements (Darzins et al., Submitted) are reported separately. This paper reports on the following research questions:

1. Do students who undertake an SCP in the early years of an entry-level occupational therapy program achieve non-inferior outcomes in their development of professional practice skills compared with those who attend a TCP, as assessed by a post-placement written examination (primary outcome), Student Practice Evaluation Form-Revised (SPEF-R) (Allison \& Turpin, 2004; Rodger et al., 2013), and overall end of semester unit result?

2. Do students and supervisors report similar professional practice learning opportunities when students complete an SCP compared to students who 
complete a TCP, assessed using frequencies of 'not applicable' and 'insufficient observation' items in the SPEF-R and student self-report survey?

3. Do students who experience an SCP report non-inferior self-confidence outcomes to those who attend a TCP, as measured by the Student Confidence Questionnaire (Derdall, Olson, Janzen, \& Warren, 2002)?

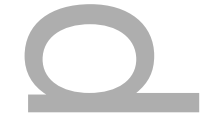

Ethical approval was provided by each participating university. The Australian Catholic University was the lead site: approval number 2014-310V. Individual participants gave informed consent to take part in the study.

\section{Design}

This was a pragmatic, non-inferiority, assessor-blind, multicentre, two-group RCT. The study protocol has been published (Imms et al., 2017).

\section{Participants and recruitment}

Eligible students were enrolled in the targeted unit of study, with an embedded placement, within six Australian occupational therapy university programs across five Australian states. Six of the targeted units were in the second of a four-year undergraduate program, the other in the first of a two-year graduate entry program. All eligible students (regardless of consent to participate) were randomised to complete either the SCP or TCP and all assessments, but only the learning outcomes data from those who consented contributed to the study. Details of the required sample size $(\mathrm{n}=$ 425) calculation can be found in the protocol paper (Imms et al., 2017).

\section{Random allocation}

Random allocation to group was carried out within sites (1:1 ratio) by the local research assistant and national project manager. Allocation of all students enrolled in the unit of study was completed at one time point and concealed from investigators and local academics by keeping the data files used to allocate students confidential until allocation was completed.

\section{Interventions}

The SCP and TCP were focused on developing students' core professional behaviours, self-management and communication skills. Participating universities had the choice of implementing a physical rehabilitation, mental health, or vocational rehabilitation SCP. Each university then located TCP opportunities in the practice This article is protected by copyright. All rights reserved 
area(s) chosen for the SCP. In total, there were nine implementations of the SCP/TCP comparison: one university implemented the trial on three campuses simultaneously, another implemented the trial in two different occupational therapy programs on separate occasions, and the remainder implemented once.

\section{The SCP intervention}

Across the five days of the SCP, students participated in simulation activities and completed tasks representative of what they might encounter during a TCP (Supplementary Figure 1 displays the week's timetable of activities). For each practice area, four detailed case studies and ten short case scenarios reflecting common occupational therapy referrals were developed in alignment with the CF-SCP and through consultation with educators from the field. Throughout the SCP, actors roleplayed the client, occupational therapists provided clinical supervision, and academic staff adopted the roles of allied healthcare practitioners and facilitated student learning. SCP students worked in three teams of three-or-four students ( nine students/team) supervised by occupational therapists from the respective practice area. Each subgroup of three students completed part of the assessment process and combined their client knowledge with that of the other two subgroups to formulate a complete understanding of the client. Each student also worked individually on a second case. At the end of the week, students presented their occupational therapy intervention plans to their clinical supervisors, received feedback and participated in a case conference.

Training (1.5 days) was provided to staff at each university to enable the local SCP coordinators to organise, prepare and implement the SCP consistently. Each university received a teaching manual to aid SCP delivery, and SCP audio-visual and written resources.

\section{The traditional clinical placement}

TCPs were to be consistent with the length of time (40-hours), intensity (oneweek block) and practice setting(s) (vocational rehabilitation, physical rehabilitation, or mental health) of the SCP implemented at each site. TCP students could be placed individually or in pairs, were supervised by one or more occupational therapists, and would observe and/or participate in setting-specific placement activities. 


\section{Data collection}

Participant age, gender, qualifications, and previous health care work experience (paid, volunteer, and placement) were collected via self-report. Depending on the variable, outcome data were collected in the week prior to placement, at the end of the placement week, and within 4 weeks of placement end or end of the semester.

\section{Outcome measures}

The written examination comprised a series of questions based on a clientfocused, scenario-based clinical report and was implemented one to four weeks after placement. We deemed an examination score difference of $\geq 7 \%$ (in $0-100 \%$ range) to be the minimally educationally meaningful difference between groups. Examinations were graded by clinical educators blinded to the students' group allocation (SCP or TCP). An examination-specific assessment rubric (Jonsson \& Svingby, 2007) was used and reliability training provided to ensure consistency across the markers (intraclass correlation coefficient (ICC) was $\geq 0.7$ ).

The end of semester unit result, including the mark (0-100\%) and grade (Higher Distinction, Distinction, Credit, Pass, Fail) were collected for each student.

The SPEF-R (Rodger et al., 2013) was used to assess placement performance. This standardised and validated instrument (Allison \& Turpin, 2004; Rodger et al., 2013 ) is used to assess professional competencies of Australian occupational therapy students in a wide range of settings. For the purposes of this study, which implemented an early years' placement, only Domains 1-4 were used: Professional Behaviour; SelfManagement Skills; Co-worker Communication; and Communication Skills.

Each student self-rated using the SPEF-R (Rodger et al., 2013) and was also evaluated by their clinical supervisor; neither could be blinded to group allocation. The rating scale is: 1 . performs unacceptably; 2. performs marginally; 3. performs adequately; 4. performs proficiently; and 5. performs with distinction. Scores of 1 or 2 indicate a fail. Students must pass all core items in each domain to achieve an overall pass in the placement, apart from Domain 2, where the minimum requirement for passing is two core, plus two other items. There is also an option to choose "not applicable" (N/A) or "insufficient observation" (I/O) for each item, either of which constitutes a pass for that item. The frequencies of items identified as N/A and I/O were used to indicate where opportunities were available but students were not observed sufficiently to determine a performance level (I/O), or where no opportunities were This article is protected by copyright. All rights reserved 
available (N/A) to learn and/or demonstrate skills and behaviours on placement. Student perceptions about their opportunities to learn the skills focused on during the SCP and TCP were also rated in response to questions using a five-point Likert scale ranging from $1=$ strongly disagree to $5=$ strongly agree.

Student confidence was assessed using the Student Level of Confidence Questionnaire (Derdall et al., 2002), developed for occupational therapy students to report on clinical placement experiences. Forty-one items are rated from 1 (strongly disagree) to 5 (strongly agree) and were averaged according to three factors determined using factor analysis: i) Student confidence about being flexible and responsive (15 items); ii) Student confidence in practice skills (14 items) and iii) Student confidence in collaboration and negotiation (12 items). Student confidence was measured immediately before and after placement.

\section{Statistical analyses}

To evaluate whether SCP students achieved non-inferior examination results to TCP students, a linear regression analysis was performed within the generalised estimating equations (GEE) framework, which also corrects for bias due to clustering effects by universities. Baseline variables demonstrating significant differences between groups were included. Three regression analyses were conducted to evaluate differences in change in confidence between the two placement types, with each post-pre difference factor as dependent variables. Independent variables included placement type (SCP or TCP), pre-placement confidence factor score (for the factor under evaluation), age group, and placement practice area.

Primary analyses were undertaken according to the placement (SCP or TCP) in which students actually participated. Findings were checked according to an intentionto-treat approach. Data were analysed without imputing missing values. Number of missing observations are reflected in the sample size for each analysis. The statistical analyses were conducted using $\mathrm{SAS}^{\mathrm{TM}}$ statistical software version 9.3 (SAS Institute Inc, 2012).

\section{RESULTS}

\section{Participation and completion rates}

Data were collected between January and November 2016. Of 694 students eligible to participate, 570 (82\%) consented (see Supplementary Figure 2). All students This article is protected by copyright. All rights reserved 
who completed the placement provided data for at least one outcome, and most students (SCP $\geq 96 \%$ of 275 ); TCP: $\geq 93 \%$ of 265 ) provided data for every outcome.

\section{Baseline characteristics}

Key baseline characteristics were similar between groups. Statistically, there were baseline differences between groups in the mental health placement allocation (Table 1), and student confidence in only one factor: Student confidence about being flexible and responsive (SCP mean (standard deviation (SD)): 3.8 (0.5); TCP mean (SD): $3.9(0.6) ; \mathrm{p}=0.041)$.

\section{Outcomes}

[insert Table 1 near here]

Question 1. Achievement of professional practice skills. Table 2 displays summary data for the examination and unit of study. There was no evidence of a difference in examination scores between groups: the mean difference between SCP and TCP favoured SCP at 1.85 (95\% Confidence Interval (CI): 0.46 to 3.24; $\mathrm{p}=0.087$ ) after adjusting for placement practice area, age group, and confidence score. The lower limit of the $95 \% \mathrm{CI}$ is 0.46 and $>-7$, providing strong evidence that SCP students achieved non-inferior results to TCP students (see Table 3). SCP students achieved a higher unit mark than those attending TCP (marginal mean difference: 1.52 (95\%CI: 0.64 to 2.4; $\mathrm{p}$ $=0.033$ ), but this difference was small. All students achieved an overall pass on the SPEF-R and passed all four domains. Analysis according to group allocation following consent (intention to treat analyses) did not influence the findings (see Table 2).

[insert Tables 2 and 3 near here]

\section{Question 2. Opportunity to practice \& demonstrate professional behaviours}

Students and educators indicated greater opportunity to demonstrate behaviours in the SCP compared to the TCP. This is evidenced by both the number of observations in the $\mathrm{SCP}$ in which a rating of N/A or I/O was given (e.g., I/O supervisor ratings $\mathrm{n}=51 \mathrm{SCP}$, $\mathrm{n}=112 \mathrm{TCP}$; student ratings $\mathrm{n}=27 \mathrm{SCP}, \mathrm{n}=66 \mathrm{TCP}$ ) as well as the difference in means between groups (see Table 4). In contrast, a higher percentage of TCP students than SCP students strongly agreed that the placement provided an opportunity to develop clinical reasoning, information gathering and documentation skills; that they could apply what they learned; and the experience was valuable (see Supplementary Table 1).

[insert Table 4 near here] 


\section{Question 3. Self-confidence outcomes}

On average, students in both groups demonstrated moderate to high confidence before and after placement (see Supplementary Table 2). The TCP group's slightly higher pre-placement confidence about being flexible and responsive on placement, than the SCP group, was maintained following the placement. When controlling for university clustering, placement practice area, age group and pre-placement confidence score, SCP students achieved a smaller increase in confidence about being flexible and responsive in comparison to TCP students (marginal mean difference; -0.16 (95\%CI: 0.25 to -0.07$) ; \mathrm{p}=0.039$ ). There were no differences between groups on the other two factors: confidence in practice skills marginal mean difference $=0.01$ (95\%CI: -0.06 to $0.09) ; \mathrm{p}=0.753$; confidence in collaboration and negotiation marginal mean difference $=0.00$ (95\% CI: -0.10 to 0.10$) ; \mathrm{p}=0.989)$.

\section{Discussion}

The findings of this RCT support the notion that SCPs designed according to the CF-SCP can substitute for TCPs in the development of occupational therapy students' professional competencies. Students who undertook an SCP embedded in early years curricula within an entry-level occupational therapy program achieved equivalent outcomes in professional practice knowledge and skills compared to those who attended a TCP. This evidence in support of replacing placements with simulation-based experiences is important: students, educators and health care providers can be assured that student competencies can be gained from a carefully designed SCP. Compared with some examples of simulation in the literature, this SCP provided a cohesive placement experience rather than focusing on students acquiring specific and discrete technical skills. The availability of manualised SCP training for educators, informed by the CFSCP, means that implementation is sustainable and consistent, and can be replicated across different practice settings.

Analysis of the SPEF-R showed SCP students and supervisors reported more opportunities to demonstrate skills (for example, explaining reasoning, communicating with stakeholders), when compared to a TCP. This supports the design of the SCP where the daily tasks were hands-on, supervised in a safe environment and delivered with consistency to all students. These findings are consistent with those of Reed (2014) who evaluated the effect on development of critical thinking skills of a combined This article is protected by copyright. All rights reserved 
simulation/traditional placement in comparison to a traditional placement in occupational therapy. This randomised trial involved 61 students and outcomes were that students exposed to simulation perceived an added value, but did not achieve different outcomes to those who attended only the traditional placement (Reed).

In contrast to SPEF-R ratings, however, when SCP students were asked directly about placement experiences they were less likely than TCP students to agree they had opportunities to practice placement-specific skills, such as developing reasoning or documentation skills. In the current study SCP students may have felt they 'missed out' on experiences because they knew their peers attending a TCP were working alongside an occupational therapist with real clients, although the extent of these opportunities varies widely across TCPs. This perception may dissipate when the SCP curriculum is implemented eonsistently across the cohort, or, as demonstrated in prior research, if the SCP is integrated with a TCP experience (Blackstock et al., 2013). Further evaluation of the students' perceptions of the value of their placement experiences is reported elsewhere (Darzins et al., Submitted).

\section{Contribution to simulation-based learning literature}

The positive findings of the value of SCP from this study are consistent with evidence from similar disciplines such as physiotherapy (Blackstock et al., 2013; Watson et al., 2012). In contrast to Blackstock et al. studies, in which the simulated experience was integral to a longer traditional placement experience, the current study provides support for a direct replacement of a short-term TCP with an SCP. The SCP examined in the current study focused on development of professional behaviours; the experiences required to develop these generic skills may differ from those needed to attain clinical competency to perform practical procedures that have often been assessed in simulation research (Liu, Schneider, \& Miyazaki, 1997). The design of the SCP was informed by the CF-SCP (Chu et al., under review), including the five criteria for quality simulation-based learning required by the Occupational Therapy Council accreditation standards: authenticity, complexity, practice immediacy, assessment, and use of multiple simulation modalities (Rodger et al., 2010). We recommend that future SCPs be designed using this framework.

The SCP utilised a high level of complexity requiring student engagement and interaction with a range of activities, including peer and supervisor interactions, This article is protected by copyright. All rights reserved 
engagement with standardised clients (actors), interviews, and community visits within a scheduled 'work-week'. This SCP was not inferior to the TCP, but it remains unclear just how complex in terms of learning experiences an SCP needs to be to replace a TCP. This SCP did not involve expensive, high-fidelity simulation technologies. Instead, detailed, realistic, practice-informed resources were developed to allow multiple opportunities for students to engage with a variety of scenarios, with each other, and with staff in placement-related roles.

As the RCT was embedded in the early years of the university programs, the one week timeframe was deemed suitable. The SCP tested in this RCT only accounted for $4 \%$ of the 1000 hours required to meet accreditation standards: the ideal length of any one SCP that aims to replace a TCP has not been established. It is possible that longer SCPs will also be effective, but it is also possible that the student experience will decline in a longer simulated placement, and costs may increase beyond what might be expected by a simple time multiplier. The ideal length of a TCP has also not been established. Evidence from this study demonstrates that students are able to achieve learning outcomes and gain confidence in either placement type.

\section{Strengths and limitations}

This fully powered, pragmatic RCT met pre-specified study design criteria in its implementation and provided robust generalizable findings. As we assessed noninferiority, a lack of difference between groups was the desired outcome. Because our sample included 540 rather than 425 students, a precise estimate of the effect was possible. Where statistically significant findings were demonstrated, the actual effects were small, typically indicating that the differences were not practically important.

Not all students received the placement they were allocated to, however this is the reality of a pragmatic trial in this setting, and in an intention-to-treat analysis the results were comparable. In contrast to the exam results in which a distribution of scores was observed, the SPEF-R pass/fail outcome did not discriminate between students: every student passed. This suggests a review of this form of assessment may be needed.

\section{Implications for education and research}

This trial's robust RCT methods, that were implemented across multiple universities employing varying occupational therapy curricula, support the generalisability of the findings that SCP are not inferior to TCP in achieving students' placement learning outcomes for those early in their degree programs. Current This article is protected by copyright. All rights reserved 
Australian accreditation standards allow for 200 of the 1000 required hours of occupational therapy practice education to be delivered through simulation-based methods (Occupational Therapy Council, 2013), but the optimal amount has not been determined, nor has whether 1000 hours is optimal for assuring graduate competence. Both these questions require further research. Further evidence is also required about the effect of repeated SCPs. The SCP conceptual framework used in this RCT provides a mechanism for a range of future questions to be addressed and for more complex inter-professional experiences to be designed. In particular, development and testing of a high level SCP used to assess graduating student core competencies prior to practice could be considered.

\section{C \\ Conclusions}

We found short-term high quality SCP can replace short-term TCP without compromising student learning. High quality simulation can be used for the purpose of developing student professional competencies related to self-management, professional behaviours and communication. The CF-SCP provides a theoretical underpinning for SCP design and may be useful in the construction of other placement replacement simulation-based learning experiences.

\section{Key points for occupational therapy}

- Students' professional behaviours and communication skills can be effectively developed using a pedagogically sound and authentic simulated placement experience;

- Short block placements comprising simulation learning methods can replace traditional placements in occupational therapy;

- The simulated placement design enables implementation in a variety of practice settings.

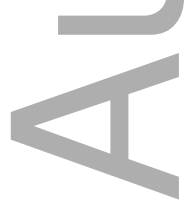

\section{References}

Allison, H., \& Turpin, M. J. (2004). Development of the student placement evaluation form: A tool for assessing student fieldwork performance. Australian 
Occupational Therapy Journal, 51(3), 125-132. doi: 10.1111/j.14401630.2004.00414.x

Bennett, S., Rodger, S., Fitzgerald, C., \& Gibson, L. (2017). Simulation in occupational therapy curricula: A literature review. Australian Occupational Therapy Journal. doi: 10.1111/1440-1630.12372

Blackstock, F. C., Watson, K. M., Morris, N. R., Jones, A., Wright, A., McMeeken, J. M., . . Jull, G. A. (2013). Simulation can contribute a part of cardiorespiratory physiotherapy clinical education: two randomized trials. Simulation in Healthcare-Journal of the Society for Simulation in Healthcare, 8(1), 32-42. doi: 10.1097/Sih.0b013e318273101a

Bradley, P. (2006). The history of simulation in medical education and possible future directions. Medical education, 40(3), 254-262. doi: 10.1111/j.13652929.2006.02394.x

Brydges, R., Hatala, R., Zendejas, B., Erwin, P. J., \& Cook, D. A. (2015). Linking simulation-based educational assessments and patient-related outcomes: a systematic review and meta-analysis. Academic Medicine, 90(2), 246-256. doi: 10.1097/ACM.0000000000000549

Chu, E.M. Y., Sheppard, L., Guinea, S., \& Imms, C. (under review). Placement replacement: A conceptual framework for designing simulated clinical placements in occupational therapy. Nursing and Health Science Journal.

Darzins, S., Ames, A., Chu, E. M. Y., Sheppard, L., Froude, E., Guinea, S., . . Imms, C. (Submitted). Simulated and traditional clinical placements: Occupational therapy students' and supervisors' perspectives of a 40 hour experience. Australian Occupational Therapy Journal.

Derdall, M., Olson, P., Janzen, W., \& Warren, S. (2002). Development of a questionnaire to examine confidence of occupational therapy students during fieldwork experiences. Canadian Journal of Occupational Therapy, 69(1), 4956. doi: org/10.1177/000841740206900105

Eagles, J. M., Calder, S. A., Wilson, S., Murdoch, J. M., \& Sclare, P. D. (2007). Simulated patients in undergraduate education in psychiatry. Psychiatric Bulletin, 31, 187-190. doi: 10.1192/pb.bp.106.010793

Eraut, M. (2007). Learning from other people in the workplace. Oxford review of education, 33(4), 403-422. doi: org/10.1080/03054980701425706

This article is protected by copyright. All rights reserved 
Eraut, M. (2010). Knowledge, Working Practices, and Learning. Learning through Practice: Models, Traditions, Orientations and Approaches, 37-58. doi: 10.1007/978-90-481-3939-2_3

Gospodarevskaya, E., Carter, R., Imms, C., Chu, E. M. Y., Nicola-Richmond, K., Gribble, N., ... Sheppard, L. (Submitted). Comparative costs of simulated and traditional clinical placements in occupational therapy. Australian Occupational Therapy Journal.

Gustafsson, L., Brown, T., McKinstry, C., \& Caine, A. M. (2016). Practice education: A snapshot from Australian university programmes. Australian Occupational Therapy Journal, 64(2), 159-169. doi: 10.1111/1440-1630.12337

Hager, P. (2011). Theories of workplace learning. The SAGE handbook of workplace learning. London: SAGE Publications Ltd.

Harder, B. N. (2009). Evolution of Simulation Use in Health Care Education. Clinical Simulation in Nursing, 5(5), e169-e172. doi: org/10.1016/j.ecns.2009.04.092 Herrington, J., \& Oliver, R. (2000). An instructional design framework for authentic learning environments. Educational Technology, Research and Development, 48(3), 23-48. doi: org/10.1007/BF02319856

Imms, C., Chu, E., Guinea, S., Sheppard, L., Froude, E., \& Carter, R. (2014). National consultation report - embedding simulation in occupational therapy. (Health Workforce Australia, Trans.). Melbourne, Australia: Australian Catholic University.

Imms, C., Chu, E. M. Y., Guinea, S., Sheppard, L., Froude, E., Carter, R., . . . Symmons, M. (2017). Effectiveness and cost-effectiveness of embedded simulation in occupational therapy clinical practice education: study protocol for a randomised controlled trial. Trials, 18(1), 345. doi: 10.1186/s13063-017-2087-

Jonsson, A., \& Svingby, G. (2007). The use of scoring rubrics: Reliability, validity and educational consequences. Educational research review, 2(2), 130-144. doi: org/10.1016/j.edurev.2007.05.002

Liu, L., Schneider, P., \& Miyazaki, M. (1997). The effectiveness of using simulated patients versus videotapes of simulated patients to teach clinical skills to occupational and physical therapy students. Occupational Therapy Journal of Research, 17(3), 159-172 doi: org/10.1177/153944929701700301

This article is protected by copyright. All rights reserved 
Mori, B., Carnahan, H., \& Herold, J. (2015). Use of simulation learning experiences in physical therapy entry-to-practice curricula: A systematic review. . Physiotherapy Canada, 67(2), 194-202. doi: 10.3138/ptc.2014-40E

Occupational Therapy Council. (2013). Accreditation Standards for Entry-Level Occupational Therapy Education Programs. Perth, WA: Occupational Therapy Council, Australia and New Zealand.

Oppermann, R., \& Specht, M. (2006). Situated learning in the process of work. In D. Hung \& M. S. Khine (Eds.), Engaged learning with emerging technologies (pp. 69-89). Dordrecht: Springer.

Reed, H. E. (2014). An Examination of Critical Thinking Skills in Traditional and Simulated Environments for Occupational Therapy Students. (Ed.D.), San Diego State University. Retrieved from http://ezproxy.acu.edu.au/login?url=https://search.ebscohost.com/login.aspx?dir ect=true $\& \mathrm{db}=\mathrm{ccm} \& \mathrm{AN}=109782221 \&$ site $=$ ehost-live Available from EBSCOhost ccm database.

Ricketts, B. (2011). The role of simulation for learning within pre-registration nursing education - A literature review. Nurse education today, 31(7), 650-654. doi: org/10.1016/j.nedt.2010.10.029

Rodger, S., Bennett, S., Fitzgerald, C., \& Neads, P. (2010). Use of simulated learning activities in occupational therapy curriculum (pp. 1-120). Brisbane, Queensland: University of Queensland on behalf of Health Workforce Australia.

Rodger, S., Chien, C. W., Turpin, M. J., Copley, J., Coleman, A., Brown, T., \& Caine, A. M. (2013). Establishing the Validity and Reliability of the Student Practice Evaluation Form-Revised (SPEF-R) in Occupational Therapy Practice Education: A Rasch Analysis. Evaluation \& the health professions, 39(1), 3348. doi: 10.1177/0163278713511456

Rodger, S., Webb, G., Devitt, L., Gilbert, J., Wrightson, P., \& McMeeken, J. (2008). Clinical education and practice placements in the allied health professions: an international perspective. Journal of allied health, 37(1), 53-62.

SAS Institute Inc. (2012). SAS 9.3: SAS Institute Inc.

Svensson, L., Ellström, P. E., \& Åberg, C. (2004). Integrating formal and informal learning at work. Journal of Workplace Learning, 16(8), 479-491. doi: org/10.1108/13665620410566441

This article is protected by copyright. All rights reserved 
Townsend, E., \& Polatajko, H. (2013). Enabling occupation II: Advancing an occupational therapy vision for health, well-being and justice through occupation. Ottawa, Canada: CAOT Publications ACE.

Watson, K., Wright, A., Morris, N., McMeeken, J., Rivett, D., Blackstock, F., . . Jull, G. (2012). Can simulation replace part of clinical time? Two parallel randomised controlled trials. Medical education, 46(7), 657-667. doi: 10.1111/j.13652923.2012.04295.x

World Federation of Occupational Therapists. (2002). Revised minimum standards for the education of occupational therapists. Forrestfield, WA: World Federation of Occupational Therapists.

Yeung, E., Dubrowski, A., \& Carnahan, H. (2013). Simulation-augmented education in the rehabilitation professions: A scoping review. International Journal of Rehabilitation and Therapy, 20, 228-236. doi: org/10.12968/ijtr.2013.20.5.228

\section{Figure legends}

Supplementary Figure 1. Summary of the activities in the five SCP days.

Supplementary Figure 2. Consort flow diagram

\section{Tables}

Table 1. Baseline characteristics: demographics.

\begin{tabular}{|c|c|c|c|c|c|c|c|c|}
\hline$C$ & & \multicolumn{2}{|c|}{ Overall } & \multicolumn{2}{|c|}{ SCP } & \multicolumn{2}{|c|}{ TCP } & \multirow[t]{2}{*}{$\begin{array}{c}\text { p- } \\
\text { value }\end{array}$} \\
\hline J & & $\mathrm{N}$ & $\%$ & $\mathrm{~N}$ & $\%$ & $\mathrm{~N}$ & $\%$ & \\
\hline \multicolumn{9}{|c|}{ Age group (years) } \\
\hline $18-19$ & & 181 & $34 \%$ & 95 & $35 \%$ & 86 & $34 \%$ & \multirow{4}{*}{0.176} \\
\hline 20 & & 136 & $26 \%$ & 74 & $27 \%$ & 62 & $24 \%$ & \\
\hline $21-22$ & & 94 & $18 \%$ & 38 & $14 \%$ & 56 & $22 \%$ & \\
\hline \multirow[t]{2}{*}{$>22$} & & 116 & $22 \%$ & 64 & $24 \%$ & 52 & $20 \%$ & \\
\hline & Total & 527 & $100 \%$ & 271 & $100 \%$ & 256 & $100 \%$ & \\
\hline
\end{tabular}

\section{Gender}

This article is protected by copyright. All rights reserved 


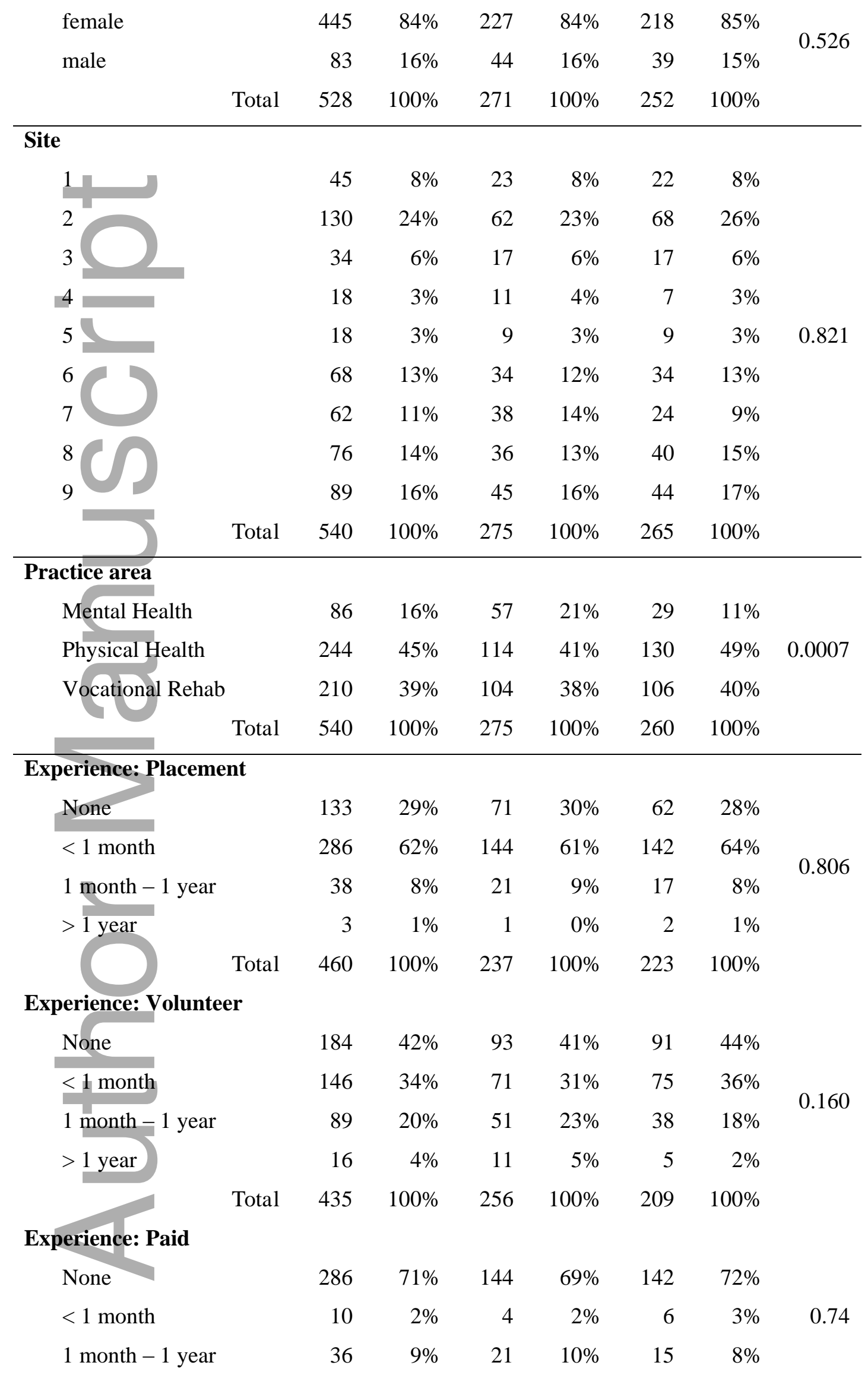

This article is protected by copyright. All rights reserved 


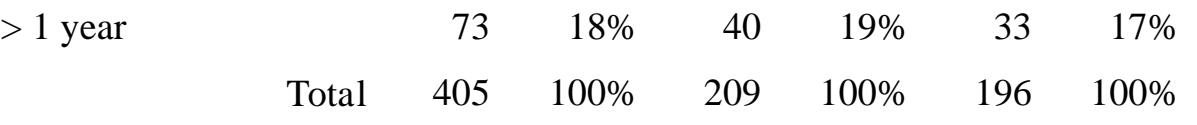

Table 2. Summary statistics for examination and unit scores for SCP and TCP students.

\begin{tabular}{|c|c|c|c|c|c|}
\hline$r=\longdiv { 2 }$ & \multicolumn{2}{|r|}{ SCP } & \multicolumn{2}{|r|}{ TCP } & $\mathbf{p}$ \\
\hline 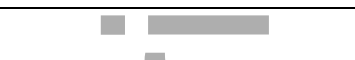 & $\mathbf{n}$ & Mean (SD) & $\mathbf{n}$ & Mean (SD) & \\
\hline Examination Score & 271 & $71.34(10.30)$ & 262 & $69.38(10.18)$ & 0.102 \\
\hline Unit score & 270 & $71.90(8.79)$ & 261 & $70.34(9.13)$ & 0.066 \\
\hline & $\mathbf{n}$ & $\%$ & $\mathbf{n}$ & $\%$ & \\
\hline Examination grade & & & & & \\
\hline High Distinction & 27 & $10 \%$ & 19 & $7 \%$ & \\
\hline Distinction & 86 & $32 \%$ & 69 & $26 \%$ & \\
\hline Credit & 87 & $32 \%$ & 85 & $32 \%$ & 0.132 \\
\hline Pass & 64 & $24 \%$ & 80 & $30 \%$ & \\
\hline Fail & 7 & $2 \%$ & 9 & $3 \%$ & \\
\hline Total & 271 & $100 \%$ & 262 & $100 \%$ & \\
\hline
\end{tabular}

\section{Unit grade}

High Distinction

Distinction

Credit

Pass

Fail

15
1
4

15

$6 \%$

8

$3 \%$

$88 \quad 33 \%$

81

$31 \%$

$19 \quad 44 \%$

118

$45 \%$

0.461

43

$16 \%$

48

$18 \%$

$5 \quad 2 \%$

6

$2 \%$

Total 270

$100 \%$

261

$100 \%$

Note: Data are summary statistics according to the placement (SCP or TCP) received.

When analysed by intention to treat, examination scores were SCP: mean 71.14 (SD: 10.39); TCP: mean 69.62 (SD: 10.13); unit score SCP: 71.77 (SD: 8.83); TCP: mean $70.50(9.12)$.

This article is protected by copyright. All rights reserved 
Table 3. Difference between groups on examination score assessed using GEE modelling to account for clustering and baseline variables.

\begin{tabular}{|c|c|c|c|c|}
\hline Parameter & Effect & Marginal Mean & $\begin{array}{l}\text { Difference } \\
(95 \% \mathrm{CI})\end{array}$ & $\mathbf{p}$ \\
\hline \multirow[t]{2}{*}{ Placement type } & $\mathrm{SCP}$ & $71.43(70.13,72.73)$ & $1.85(0.46,3.24)$ & 0.087 \\
\hline & TCP & $69.58(68.41,70.74)$ & ref & \\
\hline \multirow{3}{*}{ Placement practice area } & Mental health & $72.68(69.88,75.48)$ & $8.22(4.97,11.47)$ & 0.055 \\
\hline & Physical health & $74.37(71.9,76.84)$ & $9.91(7.0,12.81)$ & \\
\hline & Vocational & $64.46(62.97,65.96)$ & ref & • \\
\hline \multirow[t]{4}{*}{ Age group } & Age 18 or 19 & $72.17(70.78,73.56)$ & $3.18(1.9,4.47)$ & 0.055 \\
\hline & Age 20 & $71.03(69.59,72.46)$ & $2.04(0.25,3.84)$ & . \\
\hline & Age 21 or 22 & $69.84(67.55,72.14)$ & $0.86(-2.5,4.23)$ & . \\
\hline & Age over 22 & $68.98(67.43,70.54)$ & ref & . \\
\hline Pre Student confidence: & & & $0.4 .3(-2.08,2.88)$ & 0.750 \\
\hline Being flexible \& responsive & & & & \\
\hline
\end{tabular}

Table 4. Mean number of 'not applicable' and 'insufficient observation' scored by supervisors and students.

\begin{tabular}{cccccc}
\hline & SCP & \multicolumn{2}{c}{ TCP } & p \\
& N & Mean (SD) & N & Mean (SD) & \\
\hline Supervisor rating & & & & & \\
Number N/A & 86 & $1.12(0.32)$ & 90 & $2.28(1.74)$ & 0.186 \\
Number I/O & 51 & $2.71(1.74)$ & 112 & $3.00(2.24)$ & 0.751 \\
Student rating & & & & & \\
Number N/A & 22 & $1.27(0.63)$ & 65 & $2.17(1.61)$ & 0.011 \\
Number I/O & 27 & $1.70(1.64)$ & 66 & $2.71(1.98)$ & 0.017 \\
\hline
\end{tabular}

Note: $\mathrm{N} / \mathrm{A}=$ not applicable; $\mathrm{I} / \mathrm{O}=$ insufficient observation; $\mathrm{N}=$ the number of student data points contributing to the mean. A lower mean represents greater opportunity to observe/demonstrate skill.

This article is protected by copyright. All rights reserved 


\section{University Library}

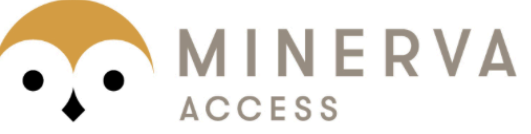

A gateway to Melbourne's research publications

Minerva Access is the Institutional Repository of The University of Melbourne

Author/s:

Imms, C;Froude, E;Chu, EMY;Sheppard, L;Darzins, S;Guinea, S;Gospodarevskaya, E;Carter, R;Symmons, MA;Penman, M;Nicola-Richmond, K;Hunt, SG;Gribble, N;Ashby, S;Mathieu, E

Title:

Simulated versus traditional occupational therapy placements: A randomised controlled trial

Date:

2018-12-01

Citation:

Imms, C., Froude, E., Chu, E. M. Y., Sheppard, L., Darzins, S., Guinea, S., Gospodarevskaya, E., Carter, R., Symmons, M. A., Penman, M., Nicola-Richmond, K., Hunt, S. G., Gribble, N., Ashby, S. \& Mathieu, E. (2018). Simulated versus traditional occupational therapy placements: A randomised controlled trial. AUSTRALIAN OCCUPATIONAL THERAPY JOURNAL, 65 (6), pp.556-564. https://doi.org/10.1111/1440-1630.12513.

Persistent Link:

http://hdl.handle.net/11343/261109 